\title{
Strategi Pengembangan Usaha Perbenihan Padi Bersertifikat di Subak Guama, Kecamatan Marga, Kabupaten Tabanan
}

\author{
NI MADE AYU CITRA LAKSMI, WAYAN WINDIA ${ }^{1)}$, KETUT SUAMBA $^{2)}$ \\ Program Studi Magister Agribisnis, Program Pascasarjana, Universitas Udayana, \\ E-mail: ayucitralaksmi@yahoo.com \\ ${ }^{1)}$ Program Studi Agribisnis, Fakultas Pertanian, Universitas Udayana \\ ${ }^{2)}$ Program Studi Agribisnis, Fakultas Pertanian, Universitas Udayana
}

\begin{abstract}
Business Development Strategy Certified Rice Seed On Subak Guama, Marga District, Tabanan Regency
\end{abstract}

The increasing rate of population growth led to increased demand for food. In order to achieve food security, the use of certified seeds is one of the factors that influence the improvement of yield and quality of production. Attempt to capture these opportunities, Subak Guama need to make strategic business development of certified rice seed. The purpose of research is to investigate alternative strategies and priorities appropriate strategies run by Subak Guama in the development of certified rice seed business.

The research location was at Subak Guama. Respondents were selected purposively regarding their expertise and knowledge of the research. Primary data were collected focus group discussions, surveys, and in-depth interviews. Secondary data were collected from publications. Formulation of alternative strategies and priority strategies using SWOT matrix analysis and analysis QSPM.

The results show alternative strategies of business development certified rice seed include: 1) expand market share in order to meet the potential needs of seeds, 2) the formation of youth groups farmer, 3) improving the quality of human resources, 4) empowerment of farmers through the capital strengthening farming 5) integrated pest and disease control, and 6) optimization of the certified rice seed business. The result also shows that the priority strategy selected is capital strengthening farming.

In supporting the development of business certified rice seed, members of Subak Guama is expected to strengthen the capital to apply for credit farming through financial institutions/banks so as to increase production and develop products seed varieties vary, increase access to a wider market so as to maintain its market position has been achieved, as well as more effective cooperation between farmers with KUAT Subak Guama.

Keywords: SWOT, QSPM, Rice Seed, Subak 


\section{PENDAHULUAN}

Pembangunan sub sektor tanaman pangan adalah meningkatkan produktivitas, kualitas dan keragaman produksi tanaman pangan serta meningkatkan pendapatan petani. Pembangunan sub sektor tanaman pangan ke depan dihadapkan pada tantangan yang cukup kompleks, diantaranya kebutuhan pangan yang terus meningkat sebagai akibat dari peningkatan jumlah penduduk, alih fungsi lahan produktif ke non produktif, tuntutan konsumen terhadap kualitas produk, persaingan pasar yang semakin ketat, serta perubahan lingkungan strategis lainnya yang akan berpengaruh terhadap pembangunan tanaman pangan.

Dalam rangka terjaminnya ketersediaan pangan dalam jumlah dan mutu yang dibutuhkan serta tingkat harga yang terjangkau dengan memperhatikan pendapatan petani, dikembangkan sistem ketahanan pangan yang berbasis pada keragaman sumber daya kelembagaan dan budaya lokal. Untuk memperkuat ketahanan pangan dan pendapatan petani, diupayakan pengelolaan usaha tani berwawasan agribisnis yang berdaya saing, berkerakyatan dan dilakukan secara berkesinambungan, salah satunya penggunaan benih bersertifikat.

Penggunaan benih bersertifikat merupakan langkah awal yang sangat menentukan terhadap input berikutnya yang diharapkan pada proses produksi. Penggunaan benih bersertifikat pada saat ini untuk komoditi padi masih rendah dan belum mampu menyediakan benih sesuai dengan kriteria enam tepat yaitu tepat mutu, tepat varietas, tepat jumlah, tepat tempat, tepat waktu dan tepat harga. Guna mewujudkan hasil yang lebih optimal, maka diperlukan penanganan secara terpadu dan berkesinambungan mulai dari hulu hingga hilir, yaitu dari penciptaan varietas, produksi, penyaluran, sosialisasi benih sumber dan benih sebar serta pengawasan mutu dibidang produksi dan peredaran benih.

Salah subak di Bali yang memproduksi benih padi bersertifikat dan sudah tersertifikasi oleh BPSB Provinsi Bali adalah Subak Guama. Peningkatan jumlah permintaan benih padi bersertifikat di Subak Guama disebabkan karena semakin pahamnya petani konsumen terhadap penggunaan benih padi bersertifikat dalam meningkatkan produktivitas, mutu hasil, nilai ekonomis produk komoditas yang dihasilkan.

Tingginya jumlah permintaan dan minat konsumen terhadap benih padi bersertifikat dapat dijadikan peluang usaha bagi Subak Guama. Upaya meraih peluang dengan memaksimalkan kekuatan dan meminimalisir kelemahan yang dimiliki, maka Subak Guama perlu berstrategi dalam mengembangkan usaha perbenihan padi bersertifikat.

Berdasarkan latar belakang tersebut, maka rumusan masalah penelitian adalah: 1) apa strategi alternatif yang dapat dijalankan oleh Subak Guama dalam pengembangan usaha perbenihan padi bersertifikat? dan 2) apa strategi prioritas yang tepat dijalankan oleh Subak Guama dalam pengembangan usaha perbenihan padi bersertifikat? Berdasarkan rumusan masalah tersebut, maka penelitian ini bertujuan untuk mengetahui: strategi alternatif yang dapat dijalankan oleh Subak Guama dalam pengembangan usaha perbenihan padi bersertifikat dan strategi 
prioritas yang tepat dijalankan oleh Subak Guama dalam pengembangan usaha perbenihan padi bersertifikat.

\section{KAJIAN PUSTAKA}

\section{Konsep Strategi}

Strategi adalah cara atau bakal tindakan yang menuntut keputusan manajemen dan dalam perumusannya diperlukan mempertimbangkan faktorfaktor internal dan eksternal yang dihadapi oleh perusahaan tersebut. Strategi adalah pola sasaran, maksud maupun tujuan dan kebijakan serta rencana-rencana penting untuk mencapai tujuan yang dinyatakan dengan cara seperti menetapkan bisnis yang dianut atau yang akan dianut oleh perusahaan

\section{Analisis Matriks SWOT}

Menurut Rangkuti (2005), analisis matriks SWOT merupakan salah suatu metode atau cara untuk menggambarkan kondisi dan mengevaluasi suatu masalah proyek atau konsep bisnis yang berdasarkan faktor internal (dalam) dan faktor eksternal (luar) yaitu strengths, weakness, oppurtunities, dan threats yang akan dilakukan analisis. Analisis SWOT hanya menggambarkan situasi yang terjadi bukan sebagai pemecah masalah. Rangkuti (2006), menyatakan matrik SWOT merupakan identifikasi berbagai faktor secara sistematis untuk merumuskan strategi yaitu strategi kekuatan-peluang ( $S-O$ strategies), strategi kelemahanpeluang ( $W$-O strategies), strategi kelemahan-ancaman ( $W$ - $T$ strategies), dan strategi kekuatan-ancaman ( $S$ - $T$ strategies).

\section{Quantitative Strategies Planning Matrix (QSPM)}

QSPM menggunakan masukan dari analitis tahap 1 dan hasil-hasil pencocokan dari analitis tahap 2 untuk memutuskan secara objektif strategi alternatif yang dapat dijalankan (David, 2004). Secara konseptual, QSPM menentukan daya tarik relatif dari berbagai strategi yang didasarkan sampai seberapa jauh faktor-faktor keberhasilan kritis eksternal dan internal kunci dimanfaatkan atau ditingkatkan. Daya tarik relatif dari masing-masing strategi dihitung dengan menentukan dampak kumulatif dari masing-masing faktor keberhasilan kritis eksternal dan internal.

\section{METODE PENELITIAN}

Penelitian ini dilakukan di Subak Guama, Kecamatan Marga, Kabupaten Tabanan. Pemilihan Subak Guama sebagai lokasi penelitian dilakukan secara sengaja.

Penentuan informan sebagai responden penentu faktor strategis internal dan eksternal menggunakan teknik penentuan responden secara sengaja. Responden yang terlibat dalam penelitian ini adalah responden yang mengetahui dengan baik kondisi internal maupun eksternal Subak Guama dalam usaha perbenihan padi 
bersertifikat yang berjumlah 11 orang. Informan kunci untuk memperoleh informasi usahatani padi merah organik dan anorganik adalah Pekaseh Subak Guama dan Manager KUAT. Informan kunci dipilih secara sengaja.

Jenis data yang digunakan adalah data primer dan sekunder. Sumber data dalam penelitian ini yaitu sumber data primer dan sekunder. Teknik pengumpulan data primer yaitu: 1) FGD, b) survey, dan wawancara mendalam. Pengumpulan data sekunder dengan studi dokumentasi terkait dengan penelitian. Instrumen utama yang digunakan dalam pengumpulan data berupa kuisioner dan kamera foto. Variabel, indikator, parameter, dan pengukuran yang digunakan pada penelitian ini disajikan pada Tabel 1.

Tabel 1.

Variabel, Indikator, Parameter, dan Pengukuran Strategi Pengembangan Usaha Perbenihan Padi Bersertifikat di Subak Guama, Kecamatan Marga, Kabupaten Tabanan

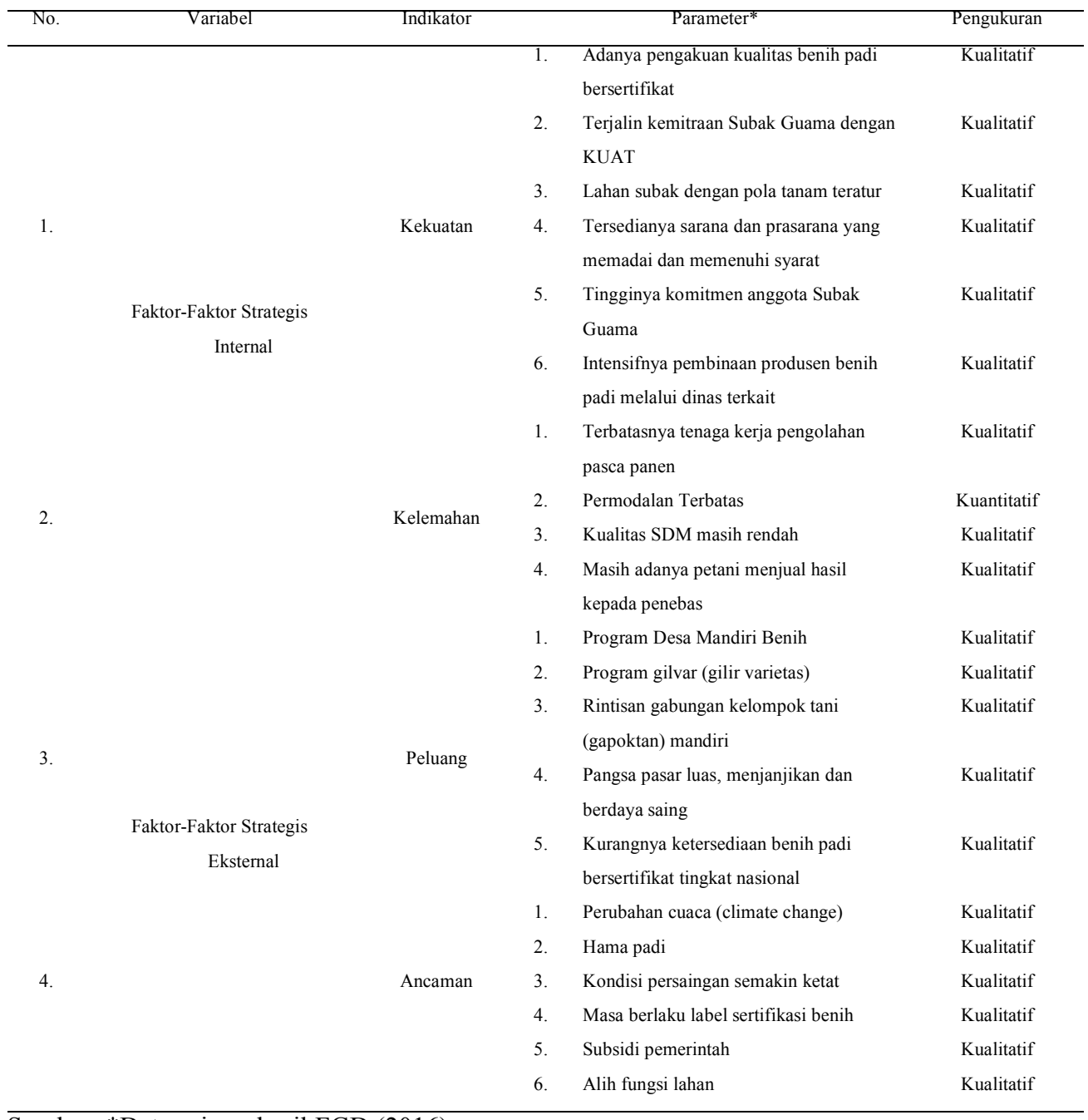

Sumber: *Data primer hasil FGD (2016) 
Hasil identifikasi faktor strategis internal (kekuatan dan kelemahan) yang dimiliki oleh Subak Wongayabetan dirumuskan ke dalam matriks IFAS. Hasil identifikasi faktor strategis eksternal (peluang dan ancaman) dirumuskan ke dalam matriks EFAS. Teknik penentuan strategi alternatif yaitu mengkombinasikan hasil yang diperoleh dari matriks IFAS dan EFAS yang dianalisis dengan matriks SWOT. Penentuan strategi prioritas dengan menggunakan analisis QSPM. Pemilihan strategi alternatif dengan QSPM dilakukan secara objektif untuk memilih strategi prioritas yang dapat dijalankan oleh Subak Guama dalam memproduksi benih padi bersertifikat.

Analisis struktur biaya pada usaha perbenihan padi besertifikat dan non bersertifikat dilakukan dengan mengelompokkan biaya tetap dan biaya variabel. Analisis pendapatan menganalisis pendapatan atas biaya tunai dan biaya total pada usaha perbenihan padi bersertifikat dan non bersertifikat. Analisis R/C ratio menilai $\mathrm{R} / \mathrm{C}$ ratio atas biaya tunai maupun atas biaya total usaha perbenihan padi berertifikat dan non bersertifikat. Analisis R/C ratio bertujuan untuk mengetahui apakah usaha perbenihan padi tersebut layak untuk diusahakan atau tidak. Hasil analisis data disajikan dalam bentuk deskriptif analisis dengan uraian/narasi, katakata, ungkapan, kalimat yang baik sesuai dengan bahasa ilmiah yang mudah dimengerti dan dipahami.

\section{HASIL DAN PEMBAHASAN}

\section{Analisis perbandingan struktur biaya usaha perbenihan padi bersertifikat dan non bersertifikat di Subak Guama}

Hasil perhitungan analisis struktur biaya dalam satu musim tanam benih padi bersertifikat dan non bersertifikat diperoleh total biaya yang dikeluarkan pada usaha perbenihan padi bersertifikat lebih sedikit sebesar Rp. 15.478.500,00 dibandingkan dengan total biaya yang dikeluarkan usaha perbenihan non bersertifikat sebesar Rp. 16.082.500,00. Hal ini disebabkan tingginya biaya tenaga kerja, biaya penggunaan pupuk dan pestisida yang digunakan dalam kegiatan usahatani produsen benih padi non bersertifikat.

\section{Analisis perbandingan pendapatan usahatani dan $\mathrm{R} / \mathrm{C}$ ratio perbenihan padi bersertifikat dan non bersertifikat di Subak Guama}

Pendapatan atas biaya tunai dan pendapatan atas biaya total per hektar per musim tanam pada usaha perbenihan padi bersertifikat lebih besar dibandingkan usaha perbenihan padi non bersertifikat. Pendapatan usahatani per hektar per musim tanam pada usaha perbenihan padi bersertifikat sebesar Rp. 22.771.500,00 dan Rp. 7.917.000,00 untuk usaha perbenihan padi non bersertifikat.Tingginya pendapatan tersebut disebabkan rata-rata penerimaan, produksi, dan harga jual benih padi bersertifikat per hektar lebih besar dibandingkan usaha perbenihan padi non bersertifikat.

Nilai $\mathrm{R} / \mathrm{C}$ ratio pada usaha perbenihan padi bersertifikat sebesar 2,47 dan 1,49 untuk usaha perbenihan padi non bersertifikat. Nilai $\mathrm{R} / \mathrm{C}$ ratio usaha 
perbenihan padi bersertifikat lebih besar dibandingkan nilai $\mathrm{R} / \mathrm{C}$ ratio usaha perbenihan padi non bersertifikat.

\section{Identifikasi Faktor-Faktor Strategis Internal dan Eksternal di Subak Guama}

Identifikasi faktor kekuatan diperoleh 6 faktor yaitu adanya pengakuan kualitas benih padi bersertifikat, terjalin kemitraan Subak Guama dengan KUAT, lahan subak dengan pola tanam teratur, tersedianya sarana dan prasarana yang memadai dan memenuhi syarat, tingginya komitmen anggota Subak Guama, dan intensifnya pembinaan produsen benih padi bersertifikat melalui dinas terkait. Kelemahan yang terdapat pada Subak Guama terdapat 4 faktor strategis yaitu terbatasnya tenaga kerja pengolahan pasca panen, permodalan terbatas, kualitas SDM masih rendah, dan masih adanya petani menjual hasil kepada penebas.

Faktor-faktor strategis eksternal (peluang dan ancaman) pada Subak Guama. Berdasarkan identifikasi faktor peluang diperoleh 5 faktor yaitu program desa mandiri benih, program gilvar (gilir varietas), rintisan gabungan kelompok tani (gapoktan) mandiri, pangsa pasar luas, menjanjikan dan berdaya saing, dan kurangnya ketersediaan benih padi bersertifikat tingkat nasional. Ancaman yang dihadapi Subak Guama terdiri dari 6 faktor yaitu perubahan cuaca (climate change), hama padi, kondisi persaingan semakin ketat, masa berlaku label sertifikasi benih, subsidi pemerintah dan alih fungsi lahan.

\section{Hasil Evaluasi Faktor Strategis Internal dan Eksternal di Subak Guama}

Hasil evaluasi faktor lingkungan internal dan eksternal menggunakan matriks IFAS dan EFAS dalam strategi pengembangan usaha perbenihan padi bersertifikat di Subak Guama.

1) Matriks IFAS strategi pengembangan usaha perbenihan padi di Subak Guama Hasil perhitungan berdasarkan matriks IFAS strategi pengembangan usaha perbenihan padi bersertifikat di Subak Guama pada Tabel 2. Faktor kekuatan utama adalah subak dengan pola tanam teratur dengan skor sebesar 0,40. Faktor kekuatan kedua yaitu adanya pengakuan kualitas benih padi bersertifikat dengan skor 0,36. Faktor kekuatan ketiga terdapat pada tingginya komitmen anggota Subak Guama dengan skor sebesar 0,35. Faktor kekuatan keempat yaitu terjalin kemitraan Subak Guama dengan KUAT dengan skor sebesar 0,32. Faktor kekuatan kelima dan keenam, yaitu tersedianya sarana dan prasarana yang memadai dan memenuhi syarat dan intensifnya pembinaan produsen benih padi melalui dinas terkait dengan masing-masing skor sebesar 0,24 dan 0,21 .

Faktor kelemahan utama pengembangan usaha perbenihan padi bersertifikat di Subak Guama berdasarkan Tabel 2 yaitu permodalan terbatas dengan skor sebesar 0,21. Faktor kelemahan kedua dan ketiga yaitu kualitas SDM masih rendah dan terbatasnya tenaga kerja pengolahan pasca panen dengan skor masing-masing sebesar 0,16 dan 0,14. Faktor kelemahan keempat yaitu masih adanya petani menjual hasil kepada penebas dengan skor sebesar 0,13 . Total skor pada matriks IFAS strategi pengembangan usaha perbenihan padi 
bersertifikat di Subak Guama sebesar 2,54 termasuk dalam kategori kuat. Hal ini menunjukkan bahwa Subak Guama mampu memanfaatkan faktor-faktor kekuatan untuk mengatasi faktor-faktor kelemahan yang dimiliki.

Tabel 2

Matriks IFAS Strategi Pengembangan Usaha Perbenihan Padi Bersertifikat di Subak Guama, Kecamatan Marga, Kabupaten Tabanan

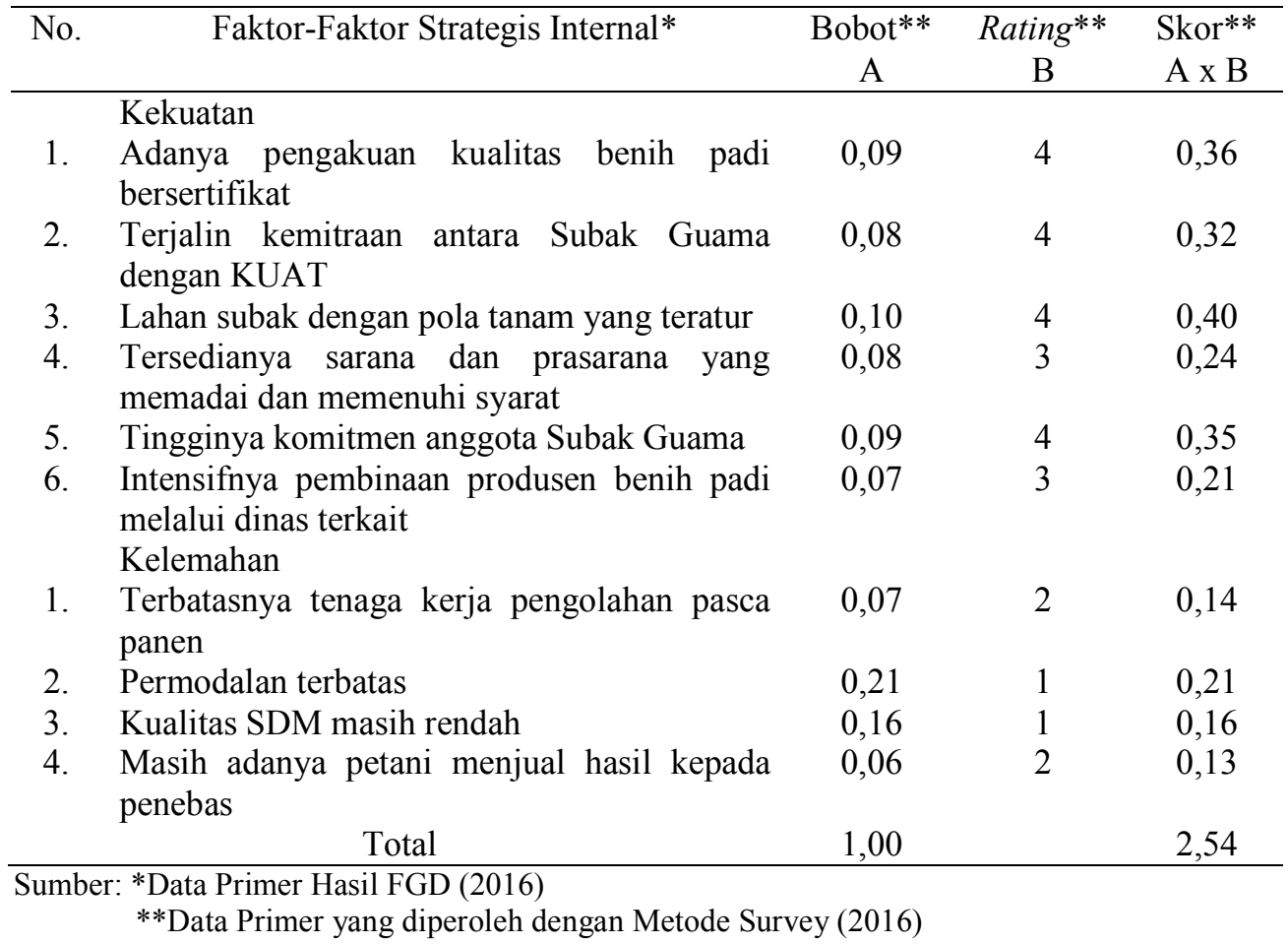

2) Matriks EFAS strategi pengembangan usaha perbenihan padi bersertifikat di Subak Guama

Hasil perhitungan berdasarkan matriks EFAS strategi pengembangan usaha perbenihan padi bersertifikat di Subak Guama seperti pada Tabel 3 yang menjadi peluang utama adalah program desa mandiri benih dengan skor sebesar 0,53 . Peluang kedua yaitu pangsa pasar luas, menjanjikan dan berdaya saing dengan skor sebesar 0,39 . Peluang ketiga adalah kurangnya ketersediaan benih padi bersertifikat tingkat nasional dengan skor 0,28. Peluang keempat dan kelima yaitu rintisan gabungan kelompok tani (gapoktan) mandiri dan program gilvar (gilir varietas) dengan skor masing-masing sebesar 0,28 dan 0,26 .

Ancaman utama berdasarkan perhitungan matriks EFAS seperti pada Tabel 3 yaitu alih fungsi lahan dengan skor 0,31 . Faktor ancaman kedua yaitu hama padi dengan skor 0,28. Hama padi ini mampu menurunkan jumlah produktivitas padi yang dibudidayakan oleh petani. Faktor ancaman ketiga adalah kondisi persaingan semakin ketat dengan skor sebesar 0,26. Faktor ancaman keempat yaitu subsidi pemerintah dengan skor 0,25. Faktor ancaman kelima dan keenam yaitu masa berlaku label sertifikat benih dan perubahan 
cuaca dengan skor masing-masing sebesar 0,15 dan 0,12 . Total skor pada matriks EFAS sebesar 3,09 mengindikasikan bahwa Subak Guama merespons positif terhadap peluang-peluang yang ada dan menghindari ancaman.

Tabel 3

Matriks EFAS Strategi Pengembangan Usaha Perbenihan Padi Bersertifikat di Subak Guama, Kecamatan Marga, Kabupaten Tabanan

\begin{tabular}{|c|c|c|c|c|}
\hline No. & Faktor-Faktor Strategis Eksternal* & $\begin{array}{c}\text { Bobot** } \\
\text { A }\end{array}$ & $\begin{array}{l}\text { Rating** } \\
\text { B }\end{array}$ & $\begin{array}{l}\text { Skor** } \\
\text { A x B }\end{array}$ \\
\hline & Peluang & & & \\
\hline 1. & Program desa mandiri benih & 0,13 & 4 & 0,53 \\
\hline 2. & Program gilvar (gilir varietas) & 0,09 & 3 & 0,26 \\
\hline 3. & $\begin{array}{l}\text { Rintisan gabungan kelompok tani (gapoktan) } \\
\text { mandiri }\end{array}$ & 0,09 & 3 & 0,28 \\
\hline 4. & $\begin{array}{l}\text { Pangsa pasar luas, menjanjikan dan berdaya } \\
\text { saing }\end{array}$ & 0,10 & 4 & 0,39 \\
\hline 5. & $\begin{array}{l}\text { Kurangnya ketersediaan benih padi bersertifikat } \\
\text { tingkat nasional } \\
\text { Ancaman }\end{array}$ & 0,09 & 3 & 0,28 \\
\hline 1. & Perubahan cuaca (climate change) & 0,06 & 2 & 0,12 \\
\hline 2. & Hama padi & 0,09 & 3 & 0,28 \\
\hline 3. & Kondisi persaingan semakin ketat & 0,09 & 3 & 0,26 \\
\hline 4. & Masa berlaku label sertifikasi benih & 0,08 & 2 & 0,15 \\
\hline 5. & Subsidi pemerintah & 0,08 & 3 & 0,25 \\
\hline 6. & Alih fungsi lahan & 0,10 & 3 & 0,31 \\
\hline & Total & 1,00 & & 3,09 \\
\hline
\end{tabular}

**Data Primer yang diperoleh dengan Metode Survey (2016)

\section{Penentuan Strategi Alternatif Pengembangan Usaha Perbenihan Padi Bersertifikat di Subak Guama}

Berdasarkan hasil yang diperoleh dari matriks IFAS dan EFAS pada Tabel 2 dan Tabel 3, disusun strategi alternatif yang dimungkinkan dapat mendukung strategi pengembangan usaha perbenihan padi bersertifikat di Subak Guama, yaitu:

1. Strategi yang menggunakan kekuatan untuk memanfaatkan kuntungan peluang yang ada (SO) yaitu:

a. Memperluas pangsa pasar guna memenuhi kebutuhan potensial benih padi bersertifikat (SO1)

Bertambahnya jumlah produsen benih dan ketatnya kondisi persaingan, maka Subak Guama perlu memperluas pangsa pasar dengan melalui promosi dan komunikasi yang tepat dan intensif, tetap menjaga mutu dan kualitas sebagai upaya peningkatan volume penjualan, mempertahankan konsumen lama dan menarik konsumen baru.

2. Strategi yang meminimalkan kelemahan dengan memanfaatkan keuntungan dari peluang yang ada (WO) yaitu: 
a. Pembentukan kelompok pemuda tani (WO1)

Tenaga kerja yang dimiliki dalam menangani pengolahan panen calon benih dan pasca panen benih padi berjumlah sedikit, usia petani yang sudah tidak produktif dan sulitnya mencari tenaga kerja di daerah setempat. Mengatasi hal tersebut maka perlu adanya pembinaan dan pelatihan kewirausahaan serta mendorong generasi muda setempat agar berperan aktif, kreatif dan inovatif guna memperlancar jalannya usaha perbenihan padi.

b. Peningkatan kualitas sumber daya manusia (WO2)

Peningkatan kualitas sumber daya manusia di bidang pertanian terus dilakukan oleh pemangku kebijakan (stakeholder) dalam hal ini adalah pemerintah. Pembangunan di sektor pertanian meliputi peningkatan kualitas SDM petani melalui melalui pemberdayaan, pembinaan serta pelatihan teknik budidaya padi

c. Pemberdayaan petani melalui penguatan modal usahatani (WO3)

Permodalan merupakan salah satu elemen esensial dalam pengembangan usaha perbenihan padi guna mendukung percepatan produksi menuju peningkatan pendapatan petani. Sebagian besar petani tidak dapat mengakses ke lembaga perbankan. Bantuan penyediaan modal disarankan dalam bentuk kredit usahatani yang mudah diakses dengan memperhatikan kondisi petani antar daerah dalam mengelola usahataninya.

3. Strategi kekuatan untuk mengatasi ancaman (ST) yaitu:

a. Pengendalian hama dan penyakit secara terpadu (ST1)

Pengendalian hama terpadu adalah konsep pengendalian hama dan penyakit tanaman yang aman bagi lingkungan dan mahluk hidup. Pada prinsipnya, pengendalian hama terpadu adalah pengendalian hama yang dilakukan dengan menggunakan kekuatan unsur-unsur alami yang mampu mengendalikan hama agar tetap berada pada jumlah dibawah ambang batas yang merugikan.

4. Strategi untuk meminimalkan kelemahan dan mengantisipasi ancaman (WT) yaitu:

a. Optimalisasi usaha perbenihan padi bersertifikat (WT1)

Meningkatkan efisiensi usaha perbenihan padi dengan cara meningkatkan manajemen pengelolaan berdasarkan kemampuan finansial produsen benih dengan mempertimbangkan permintaan (pasar).

\section{Rekomendasi Strategi Prioritas Pengembangan Usaha Perbenihan Padi Bersertifikat di Subak Guama}

Hasil analisis QSPM, strategi terbaik yang harus diprioritaskan yaitu strategi intensifikasi pemberdayaan petani melalui penguatan modal usahatani dengan skor tertinggi sebesar 6,26 berdasarkan nilai TAS. Modal yang dimiliki Subak Guama dalam memproduksi benih padi bersertifikat diperoleh melalui pinjaman bank. Namun, Subak Guama masih belum mampu memproduksi benih padi dengan varietas yang beragam secara maksimal sesuai dengan permintaan 
konsumen dikarenakan terbatasnya modal yang dimiliki. Bantuan penyediaan modal usahatani, disarankan dalam bentuk kredit dengan bunga ringan dan syarat yang mudah melalui peningkatan pendekatan petani ke mekanisme perbankan atau lembaga keuangan serta memperhatikan variasi kebiasaan petani antar daerah dalam pengelolaan usahatani. Modal yang dimiliki oleh Subak Guama, tidak semata hanya untuk menjalankan unit penangkaran benih padi tetapi juga untuk menjalankan unit usaha lain, seperti usaha integrasi sistem padi ternak dan simpan pinjam. Dari aspek ekonomi, keuntungan finansial tertinggi terletak pada unit usaha penangkaran benih padi dan kredit usaha mandiri/simpan pinjam. Sehingga, dengan adanya modal yang cukup Subak Guama dapat meningkatkan volume pengadaan benih secara maksimal sesuai dengan kebutuhan konsumen guna mendukung keberlanjutan usaha penangkaran benih padi bersertifikat.

\section{SIMPULAN DAN SARAN}

\section{Simpulan}

1. Strategi-strategi alternatif yang dapat dilaksanakan oleh Subak Guama berdasarkan analisis matriks SWOT yaitu: 1) memperluas pangsa pasar guna memenuhi kebutuhan potensial benih padi bersertifikat, 2) pembentukan kelompok pemuda tani, 3) peningkatan kualitas sumber daya manusia, 4) Pemberdayaan petani melalui penguatan modal usahatani, 5) pengendalian hama dan penyakit secara terpadu, dan 6) optimalisasi usaha perbenihan padi bersertifikat.

2. Strategi prioritas yang dapat dilaksanakan oleh Subak Guama dalam strategi pengembangan usaha perbenihan padi bersertifikat adalah pemberdayaan petani melalui penguatan modal produsen benih sehingga terpenuhinya kebutuhan benih padi bersertifikat baik dalam kuantitas, kualitas, maupun kontinuitas.

\section{Saran}

1. Diharapkan kepada produsen benih Subak Guama agar lebih meningkatkan kerjasama dengan KUAT, diantaranya dengan tidak menjual calon benih kepada penebas dan lebih mengefektifkan KUAT sebagai lembaga pertanian Subak Guama yang memasarkan hasil produksi sehingga petani tidak mengalami kerugian.

2. KUAT selaku lembaga pertanian di bawah Subak Guama yang menangani pengelolaan unit-unit usaha ekonomi dan penyediaan modal bagi anggota Subak Guama khususnya dalam usaha penangkaran benih padi bersertifikat. Diharapkan KUAT berkoordinasi dengan pemerintah dalam penyediaan modal tersebut melalui pinjaman dari lembaga keuangan/perbankan lainnya sehingga dengan adanya modal yang cukup, Subak Guama dapat meningkatkan volume pengadaan benih secara maksimal sesuai dengan kebutuhan konsumen guna mendukung keberlanjutan usaha penangkaran benih padi bersertifikat. 


\section{DAFTAR PUSTAKA}

BPS Provinsi Bali. 2014. a Bali Dalam Angka. Denpasar: Badan Pusat Statistik Provinsi Bali.

. 2015. b Statistik Tanaman Padi dan Palawija Provinsi Bali. Denpasar: Badan Pusat Statistik Provinsi Bali.

— 2014. b Statistik Indonesia. Jakarta: Badan Pusat Statistik.

Craig, J. C, dan Grant, R. M. 1993. The Fast-Track MBA Series Strategic Management. Jakarta: PT Elex Media Komputindo.

David, R. F. 2004. Manajemen Strategi: Konsep-Konsep. (Kresno Suroso. Penj.). Jakarta: PT Indeks.

Direktorat Jenderal Tanaman Pangan Provinsi Bali. 2015. Keputusan Menteri Pertanian Republik Indonesia Tentang Pedoman Teknis Produksi Benih Bina Tanaman Pangan.

Jatmiko, RD. 2003. Manajemen Stratejik. Malang: Universitas Muhammadiyah Malang.

Muhammad, S. 2008. Manajemen Stratejik Konsep dan Kasus. Yogyakarta: Sekolah Tinggi Ilmu Manajemen YKPN.

2006. Analisis SWOT Teknik Membedah Kasus Bisnis. Jakarta: PT Gramedia Pustaka Utama.

Sriasih. 2006. Strategi Pengembangan Usaha Perbenihan Padi di Kaupaten Tabanan Kasus kelompok tani penangkar benih Subak Sungsang, Desa Tibubiyu, Kecamatan Kerambitan, Kabupaten Tabanan (tesis). Program Pascasarjana. Program Studi Agribisnis. Denpasar:Universitas Udayana.

UPT. BPSB. 2014. Bali Dalam Angka. Bali: Unit Pelaksana Teknis Balai Pengawasan dan Sertifikasi Benih. Bali. 